Sağnak, M. / Journal of Yasar University, 2020, 15/59, 615-623

\title{
Depo Yeri Seçimi: Perakende Sektöründe Melez Çok Kriterli Karar Verme Uygulaması
}

\author{
Warehouse Location Selection: Hybrid Multi-Criteria Decision-Making \\ Application in Retail Sector
}

\author{
Muhittin SAĞNAK, İzmir Katip Çelebi Üniversitesi, Türkiye, muhittin.sagnak@ikcu.edu.tr \\ Orcid No: 0000-0002-0799-0348
}

\begin{abstract}
Öz: Günümüzün hızla gelişen iş dünyasında, lojistik ve tedarik zinciri yönetimi gittikçe daha önemli hale gelmektedir. Bu bağlamda, depolar, tedarik zinciri boyunca bütün organizasyonlar ve faaliyetler arast iletişimi sağlayan önemli bă̆lantı noktalarıdır. Depo yeri seçimi bu nedenle tedarik zinciri üzerindeki etkisi nedeniyle önemli bir karar sorunudur. Bu çalışmada, perakende sektöründe faaliyet gösteren büyük bir kuruluş için bulanık Analitik Hiyerarşi Süreci (AHS) ve bulanık TODIM teknikleri entegre edilerek en uygun depo yeri seçiminin yapılması hedeflenmiştir. En uygun depo yeri seçimi için geliş̧tirilen kriter seti, diğer bir deyişle kavramsal çerçeve, literatür taraması ile gelişstirilmiştir. Bulanık AHS kriterlerin önem ağırlıklarının bulunmasında kullanılmış, alternatifler ise bulanık TODIM tekniği kullanılarak değerlendirilmiş̧tir. Çıkan sonuçlara bağll çıkarımlar geliştirilmiş̧tir.
\end{abstract}

Anahtar Kelimeler: Tedarik Zinciri, Depo Yeri Seçimi, Bulanık Analitik Hiyerarşi Süreci, Bulanık TODIM JEL Siniflandirmast: C18, M11, M19

Abstract: In today's rapidly developing business world, logistics and supply chain management are becoming more and more important. In this context, warehouses are important connection points that provide communication between all organizations and activities throughout the supply chain. Warehouse location selection is, therefore, an important decision problem due to its impact on the supply chain. In this study, it is aimed to select the most appropriate warehouse location by integrating the fuzzy Analytical Hierarchy Process (AHP) and fuzzy TODIM techniques for an organization operating in the retail sector. The criteria set developed for the selection of the most suitable warehouse location, in other words, the conceptual framework has been developed by literature review. Fuzzy AHP was used to find the importance weights of the criteria. Alternatives were evaluated using the fuzzy TODIM technique. Some implications have been developed based on the results.

Keywords: Supply Chain, Warehouse Location Selection, Fuzzy Analytic Hierarchy Process, Fuzzy TODIM JEL Classification: C18, M11, M19

\section{Giriş}

Tedarik zinciri, ürünlere değer katarak hammaddelerin nihai ürünlere dönüştürülmesi, nihai ürünlerin talep noktalarına aktarılması ve ağın paydaşları arasındaki bilgi akışlarının basitleştirilmesi için koordine edilen entegre bir ağdır. Tedarik zinciri ă̆ süreci üç karar düzeyi içerir: (1) tesislerin sayısı, yeri ve kapasitesi; (2) tedarikçi, kanal ve nakliye modlarının seçimi ve ürünlerin atanması ve (3) malzeme akışı (Amiri, 2006). Stratejik tedarik zinciri kararlarından biri olarak, yer seçimi hem akademik hem de iş hayatında büyük ilgi görmüştür (Kapoor vd., 2008), çünkü şirketlerin uzun vadeli kârlarını doğrudan etkilemektedir (Queiruga vd., 2008). Bu kritik kararın kısa vadeli kararlarla karşılaştırılması zordur, çünkü geri dönülmesi zor bir karardır ve yüksek derecede belirsizlik içerir (Snyder, 2006). Tipik bir tedarik zincirinde belirsizlikler temel olarak aşağıdaki sorunlardan kaynaklanabilir (Bhatnagar ve Sohal, 2005):

- tedarikçiler (tedarikçiler tarafından zamanında yapılan teslimatlar, dolum siparişlerindeki ortalama tedarikçi kalitesi, vb.);

- $\quad$ üretim süreci (planlanan duruş süresi, planlanmamış duruşların süresi, vb.); ve

- müşteriler (aylık talep ön ödemelerinin ortalama doğruluğu, müşteri tabanının boyutu vb.).

$\mathrm{Bu}$ koşullar altında, alternatif yerlerin değerlendirilmesi için etkili ve uygulanabilir bir süreç geliştirmek zorlaşmaktadır (Temur, 2016).

Günümüzün hızla gelişen iş dünyasında, lojistik ve tedarik zinciri yönetimi gittikçe daha önemli hale gelmektedir (Demirel vd., 2010). Bu bağlamda, depolar, yerel veya küresel pazarlarda bir tedarik zinciri ağında çok önemli bağlantılardır. Tedarik zinciri ağındaki depo konumu tedarik zincirlerinin verimliliğini ve hızını belirler. Mevcut bağlamda, tedarik zincirleri esas olarak teslimat sağlama süresi ve toplam ürün maliyeti açısından birbirleriyle rekabet halindedir. (Singh vd., 2018). Depo, hammaddelerin veya imal edilen malların satışa sunulmadan önce depolanabileceği büyük bir binadır. Genel uygulamada, üretim biriminden gelen mallar, piyasadaki talebe göre farklı satıcılara verildiği bir depoya gönderilir.

\section{Makale Gecmissi / Article History}

Başvuru Tarihi / Date of Application

Kabul Tarihi / Acceptance Date

: 14 Şubat / February 2020

: 16 Nisan / April 2020

(c) 2020 Journal of Yaşar University. Published by Yaşar University. Journal of Yaşar University is an open access journal.

There is no conflict of interest or ethical concern regarding this publication. 
Tedarik zinciri yönetimi, mal akışı, ne üretilmesi, ne kadar üretilmesi ve farklı seviyelerde bilgi paylaşımı ile ilgili olmanın yanı sıra, sürecin her aşamasında ne kadar depolanacağı ve en önemlisi yerel veya küresel depo yeri seçilmesi ile de ilgilidir. Her firma, belirli hedeflere ulaşmak için tedarik zincirini daha verimli hale getirmeye çalışır. Pazara giriş ve müşteri desteği gibi tedarik zinciri hedeflerine ulaşmak için depo ile ilgili faktörler önemli bir rol oynamaktadır (Singh vd., 2018). Böylece, bir firmanın bir deposunun yerleşimi, yeri ve tasarımı hakkında çeşitli kararlar alması önemli hale gelir.

Tedarik zinciri yönetimi, yer seçimi ve ürün kalitesinden büyük ölçüde etkilenmektedir (Heizer ve Render, 2006). Sermaye yatırımı, işletme giderleri ve müşteri hizmetleri depo yeri seçimine ilişkin kararlardan etkilenir. Günümüzde depolama, etkili küresel tedarik zinciri ağı için en önemli sağlayıcılardan biri haline gelmiştir (Singh vd., 2018).

Tedarik zincirinin uygun şekilde entegrasyonu pazarın rekabet edebilirliğindeki en önemli konulardan biridir. Bu bağlam, tedarik zinciri yönetimi kapsamında depo faaliyetlerinin literatürdeki önemini vurgulamaktadır. Depo faaliyeti, lojistik kanalının entegrasyonunda temel öneme sahip bir unsurdur ve üretimin bir uzantısı olarak kabul edilmektedir (da Silva vd., 2015).

Depo sistemi işlevi, alma, depolama ve sipariş toplama (taleplerin ayrılması) ile ilgili bir dizi faaliyetten oluşur (Rouwenhorst vd., 2000). Dağıtım depolarının optimum konumu, lojistik sistemlerinin optimizasyonunun önemli bir kısmi görevidir. Ürünlerin hammadde tesislerinden işleme tesislerine, bileşen üretim tesislerine, bitmiş ürün montaj tesislerine, dağıtım merkezlerine, depolara, perakendecilere ve müşterilere verimli ve etkili bir şekilde taşınması günümüzün rekabetçi ortamında kritik öneme sahiptir. (Demirel vd., 2010).

Depo yeri seçimi tedarik zinciri üzerindeki etkisi nedeniyle önemli bir karar sorunudur (Aktepe ve Ersöz, 2014). Bu nedenle, bu tür problemleri çözmek için çeşitli yöntemler kullanılır. Dağıtım ağının verimliliğine katkıda bulunmak, maliyetleri en aza indirmek ve insanların çoklu kriterler arasından en iyi alternatifi seçmelerine yardımcı olmak amacıyla çok kriterli karar verme teknikleri karar verme sürecini etkin bir şekilde yürütmek için kullanılır. Çok kriterli karar verme teknikleri, birçok çelişkili ölçüt içeren değerlendirme ve sıralama problemlerinin çözümü için yaygın olarak kullanılan bir metodolojidir (Emeç ve Akkaya, 2018).

Belirsizlik altında değerlendirilen problemler için çözüm tekniklerinin geliştirilmesi, karar vericilerin ve araştırmacıların sistemin en kötü durum performansını göz önünde bulundurarak çözüm üretmeleri için yüksek bir önceliktir. Aksi takdirde, kararlar beklenmedik durumların çoğunun gerekli önlemleri alması için etkili bir şekilde öngörüde bulunamaz, tedarik zinciri riskini azaltamaz ve böylece şirketlerin rekabet gücünü ve karlılığını artıramaz (Temur, 2016). Bu sebeple, bu çalışmada çok kriterli karar verme tekniklerinin entagrasyonu ile, hem nicel hem de nitel değişkenlerin ölçülebilir duruma getirilmesi hedeflenmiştir.

$\mathrm{Bu}$ çalışmada, perakende sektöründe faaliyet gösteren bir firma için bulanık Analitik Hiyerarşi Süreci (AHS) ve bulanık TODIM teknikleri entegre edilerek en uygun depo yeri seçiminin yapılması hedeflenmiştir. En uygun depo yeri seçimi için geliştirilen kriter seti, diğer bir deyişle kavramsal çerçeve, literatür taraması ile geliştirilmiştir. Bulanık AHS kriterlerin önem ağırlıklarının bulunmasında kullanılmış, alternatifler ise bulanık TODIM tekniği kullanılarak değerlendirilmiştir. Bu çalışmanın özgün niteliği, 1) depo yeri seçimi için geliştirilen kriter setinin kapsayıcı olması, 2) TODIM tekniğinin depo yeri seçimi için kullanılmasıdır.

Giriş bölümünü takiben, bu çalışmanın ikinci bölümünde depo yeri seçimi ile ilgili yapılmış geçmiş çalışmalara yer verilmiştir. Üçüncü bölüm, depo yeri seçimi için geliştirilen kavramsal çerçevenin sunulduğu, dördüncü bölüm, uygulanan tekniklerin açıklandığı bölümdür. Beşinci bölüm, uygulamayı ve sonuçları ifade etmekte, son olarak, altıncı bölüm ise çıkarımları ve tartışma bölümünü içermektedir.

\section{Literatür Taraması}

Son yıllarda depo yeri seçim problemi literatürü dikkate alındığında farklı yöntemlerin kullanıldı̆̆ı görülmektedir (Emeç ve Akkaya, 2018). Sezgisel yöntemler, matematiksel programlama modelleri ve çok kriterli karar verme teknikleri bunlardan bazılarıdır.

Kalfakakou vd. (2003), eşzamanlı depolamada kısıtlamaları karşılayan ürünleri depolamak için gereken en az sayıda depo arayan sezgisel bir yöntem geliştirmişlerdir. Michel ve Van Hentenryck (2004), depo yeri problemi için basit, sağlam ve verimli bir tabu-arama algoritması geliştirmişlerdir. Askin vd. (2014) (i) açılacak depoların yerini ve kapasite seviyesini; (ii) her üretim tesisinden her perakendeci çıkışına dağıtım yolunu ve (iii) her bir depoda ve perakendecide stoklanan ürün miktarını belirlemek amacıyla karmaşık bir tesis yeri sorununu çözmek için genetik algoritmayı kullanmışlardır. Yaobao vd. (2013), parçacık sürü optimizasyonu kullanarak bir otomobil yedek parça deposu yer seçimi probleminde depo sınırlamaları dahilinde mevcut depolama alanını en üst düzeye çıkarmak için malların optimum tahsisini belirlemişlerdir. Rath ve Gutjahr (2014), afet yardımında üç-amaçlı depo yeri-yönlendirme problemini çözmek için sezgisel yöntem geliştirmişlerdir. Abo-Elnaga vd. (2017), aktif setli güven bölgesi algoritması kullanarak toplam dağıtım maliyetini en aza indirgemek için bir dizi talep merkezi tedarik edecek servis merkezinin (depoların) sayısını ve büyüklüğünü belirlemişlerdir.

Baker (1982), tüm talepleri minimum toplam maliyetle karşılamak için, her bir depodan hangi malların taşınacağını belirlemek için karma tamsayı programlama modelini kullanmıştır. Aghezzaf (2005), belirsiz taleplere sahip tedarik zincirleri için planlar geliştirmek üzere kapasite planlaması ve depo yeri problemini çözmek amacıyla karma-tamsayı 
programlama modelini kullanmıştır. Gill ve Bhatti (2007) depo yeri ve perakendeci tahsisi problemini 0-1 tamsayı programlama problemi olarak modellemiş ve büyük boyutlu problemleri çözmek için sezgisel algoritmayı kapsayan iki aşamalı bir çözüm sağlamışlardır. Brahimi ve Khan (2014) üretim, envanter ve dağıtım kararları ile depo yeri seçimi için karma tamsayı programlama modelini kullanmışlardır. Chen vd. (2017), birbirine bağlı depo ağlarındaki çevrimiçi perakendeciler için depo yeri seçimi amacıyla karışık tamsayı programlama modelini kullanmışlardır. Benalcazar vd. (2017), karma tamsayı programlama modeli kullanarak kömür üreten veya ticaret yapan bir şirketin depolama ve dağıtım ağının yeniden yapılandırılmasını sağlamışlardır. Brunaud vd. (2018), karma tamsayı programlama modelini kullanarak mevsimsel talep ile uzun vadeli bir tahmini desteklemek için gerekli olan depoların optimal sayısını, yerini ve kapasitesini belirlemişlerdir.

Demirel vd. (2010) büyük bir lojistik firmasının gerçek bir depo yeri seçim problemine çok kriterli Choquet integrali uygulamışlardır. Chatterjee ve Kar (2013), bulanık Rasch-VIKOR yöntemini kullanarak riskli ortamdaki bir dizi potansiyel alternatif noktadan en uygun ve en düşük riskli depo yerini belirlemişlerdir. Aktepe ve Ersöz (2014), lojistik maliyetlerini en aza indirgemek amacıyla depo yeri seçimi sorununu çözmek için AHS, VIKOR ve MOORA olmak üzere üç farklı yöntemi birleştirmişlerdir. Durmuş ve Türk (2014), lojistik regresyon modelini kullanarak, depoların yer seçimini etkileyen faktörleri ve önem derecelerini araştırmışlardır. Temur (2016) CBDO adlı yüksek belirsizlikle mücadele eden yeni bir destekleyici karar aracı geliştirmiş ve önerilen model depo yeri seçim problemine uygulanmıştır. Dey vd. (2016), TOPSIS, SAW ve MOORA kullanarak yöneticileri depo yeri seçim problemine stratejik bir çözüme doğru yönlendirerek tedarik zincirinin verimliliğini ve dolayısıyla karlılığını artırmayı hedeflemişlerdir. Dey vd. (2017), depo yeri problemi için ikili karşılaştırma matrislerine dayalı yeni bir yaklaşım önererek çok kriterli grup karar verme metodolojisini geliştirmişlerdir. He vd. (2017), alternatif acil depo konumlarını değerlendirmek amacıyla ELECTRE-II yöntemini kullanmışlardır. Emeç ve Akkaya (2018) stokastik AHS ve bulanık VIKOR kullanarak belirsiz durum içeren stokastik ortamda depo yeri problemini çözmek için çok kriterli bir karar verme yaklaşımı geliştirmişlerdir. Hakim ve Kusumastuti (2018), AHS kullanarak yardım depolarının yerini belirlemek için bir karar verme modeli belirlemişlerdir. Singh vd. (2018), bulanık AHS kullanarak depo yeri seçimi için farklı kriterler temelinde, İran'daki çeşitli özel ekonomik bölgelerde ve serbest ticaret bölgelerinde bir depo için en uygun yerin seçimini sağlamışlardır.

Tablo 1, depo yeri seçim problemi ile ilgili literatürü göstermektedir.

Tablo 1. Depo Yeri Seçimi Literatürü

\begin{tabular}{|c|c|}
\hline Yazarlar & Yöntem \\
\hline Abo-Elnaga vd., 2017 & Active-set trust-region algoritmas1 \\
\hline Aghezzaf, 2005 & Karışık Tamsayı Programlama Modeli \\
\hline Askin vd., 2014 & Genetik Algoritma \\
\hline Baker, 1982 & Karışık Tamsayı Programlama Modeli \\
\hline Benalcazar vd., 2017 & Karışık Tamsayı Programlama Modeli \\
\hline Brahimi ve Khan, 2014 & Karışık Tamsayı Programlama Modeli \\
\hline Brunaud vd., 2018 & Karışık Tamsayı Programlama Modeli \\
\hline Chatterjee ve Kar, 2013 & Bulanık Rasch-VIKOR \\
\hline Chen vd., 2017 & Karışık Tamsayı Programlama Modeli \\
\hline Demirel vd., 2010 & Choquet İntegral \\
\hline Dey vd., 2016 & TOPSIS, SAW ve MOORA \\
\hline Dey vd., 2017 & Çok Kriterli Grup Karar Verme \\
\hline Durmuş ve Türk, 2014 & Lojistik Regresyon \\
\hline Emeç ve Akkaya, 2018 & Stokastik AHS ve Bulanık VIKOR \\
\hline Gill ve Bhatti, 2007 & 0-1 Tamsayı Programlama Modeli \\
\hline Hakim ve Kusumastuti, 2018 & AHS \\
\hline He vd., 2017 & ELECTRE-II Yöntemi \\
\hline Kalfakakou vd., 2003 & Grafik Teorisi \\
\hline Michel ve Van Hentenryck, 2004 & Tabu Search \\
\hline Singh vd., 2018 & Bulanık AHS \\
\hline Yaobao vd., 2013 & Parçacık Sürü Optimizasyonu \\
\hline Rath ve Gutjahr, 2014 & Sezgisel Yöntem \\
\hline Aktepe ve Ersöz, 2014 & AHS, VIKOR ve MOORA \\
\hline
\end{tabular}




\section{Kavramsal Çerçeve}

Depo yeri seçimi, tedarik zincirinin önemli kararlarından biridir. Bu bağlamda, depo yeri seçimi için kullanılacak kavramsal çerçeve gerekli olan nitel ve nicel faktörleri ve metrikleri içermektedir.

Tablo 2, depo yeri seçiminde kullanılacak faktörleri göstermektedir. Bu faktörlerden oluşan kavramsal çerçeve, detaylı literatür taraması sonunda oluşturulmuştur.

Tablo 2. Depo Yeri Seçimi Kavramsal Çerçeve

\begin{tabular}{|c|c|}
\hline Kriterler & Kaynakça \\
\hline Taşıma Maliyeti & $\begin{array}{l}\text { Abo-Elnaga vd., 2017; Aghezzaf, 2005; Chen vd., 2017; Askin vd., 2014; } \\
\text { Baker, 1982; Benalcazar vd., 2017; Brahimi ve Khan, 2014; Brunaud vd., 2018; } \\
\text { Michel ve Van Hentenryck, 2004; Demirel vd., 2010; Emeç ve Akkaya, 2018; } \\
\text { Hakim ve Kusumastuti, 2018; Onstein vd., } 2019\end{array}$ \\
\hline Satış Tahmini (Talep) & $\begin{array}{l}\text { Abo-Elnaga vd., 2017; Aghezzaf, 2005; Chen vd., 2017; Askin vd., 2014; } \\
\text { Baker, 1982; Benalcazar vd., 2017; Brahimi ve Khan, 2014; Brunaud vd., 2018; } \\
\text { Kalfakakou vd., 2003; Onstein vd., 2019; Singh vd., } 2018\end{array}$ \\
\hline Depo Yatırım Maliyeti & $\begin{array}{l}\text { Abo-Elnaga vd., 2017; Aghezzaf, 2005; Askin vd., 2014; Baker, 1982; } \\
\text { Benalcazar vd., 2017; Brahimi ve Khan, 2014; Brunaud vd., 2018; Michel ve } \\
\text { Van Hentenryck, 2004; Emeç ve Akkaya, 2018; Hakim ve Kusumastuti, 2018; } \\
\text { He vd., 2017; Onstein vd., 2019; Özcan vd., 2011; Singh vd., } 2018\end{array}$ \\
\hline Depo Kapasitesi & $\begin{array}{l}\text { Askin vd., 2014; Benalcazar vd., 2017; Brahimi ve Khan, 2014; Kalfakakou vd., } \\
\text { 2003; Emeç ve Akkaya, 2018; He vd., 2017; Özcan vd., } 2011\end{array}$ \\
\hline Teslim Süresi & Askin vd., 2014; Demirel vd., 2010; Emeç ve Akkaya, 2018; Onstein vd., 2019 \\
\hline Çalışan Maliyeti & Demirel vd., 2010; Emeç ve Akkaya, 2018; Onstein vd., 2019 \\
\hline $\begin{array}{l}\text { Çeşitli Taşıma Opsiyonlarının } \\
\text { Varlığı }\end{array}$ & Demirel vd., 2010; Dey vd., 2016; Dey vd., 2017 \\
\hline Müşterilere Yakınlık & $\begin{array}{l}\text { Demirel vd., 2010; Dey vd., 2016; Emeç ve Akkaya, 2018; Hakim ve } \\
\text { Kusumastuti, 2018; Özcan vd., 2011; Singh vd., } 2018\end{array}$ \\
\hline Tedarikçilere Yakınlık & $\begin{array}{l}\text { Demirel vd., 2010; Emeç ve Akkaya, 2018; Hakim ve Kusumastuti, 2018; } \\
\text { Özcan vd., } 2011\end{array}$ \\
\hline Üreticilere Yakınlık & Demirel vd., 2010; Emeç ve Akkaya, 2018 \\
\hline Arazi Uygunluğu & Dey vd., 2016; Dey vd., 2017; Hakim ve Kusumastuti, 2018 \\
\hline Vergi Politikası & Demirel vd., 2010; Dey vd., 2016; Onstein vd., 2019; Singh vd., 2018 \\
\hline $\begin{array}{c}\text { Altyapı (Su, Telekomünikasyon, } \\
\text { Elektrik) }\end{array}$ & $\begin{array}{l}\text { Demirel vd., 2010; Emeç ve Akkaya, 2018; Hakim ve Kusumastuti, 2018; Singh } \\
\text { vd., } 2018\end{array}$ \\
\hline Güvenlik & Hakim ve Kusumastuti, 2018 \\
\hline
\end{tabular}

Kavramsal çerçeve kapsamında yer alan depo yeri seçimine ait kriterlerden bazıları nesnel, bazıları ise öznel kriterlerdir. Nesnel kriterler, ikili karşılaştırma matrisleri kapsamında karar vericilerin nesnel verilere dayanarak veri oluşturduğu, öznel kriterler ise öznel değerlendirmelerini yansıttıkları kriterlerdir. Taşıma maliyeti, satış tahmini (talep), depo yatırım maliyeti, depo kapasitesi, teslim süresi, çalışan maliyeti, çeşitli taşıma opsiyonlarının varlığı, müşterilere yakınlık, tedarikçilere yakınlık, üreticilere yakınlık, arazi uygunluğu ve vergi politikası kriterleri nesnel kriterler; altyapı (su, telekomünikasyon, elektrik) ve güvenlik öznel kriterlerdir.

Öte yandan, kavramsal çerçevede yer alan kriterlerin bir kısmı, yüksek olduğunda olumsuz etki yaratacak maliyet kriterleri, bir kısmı ise yüksek olduğunda olumlu etki yaratacak fayda kriterleridir. Bu bağlamda, maliyet tipi kriterler; taşıma maliyeti, depo yatırım maliyeti, çalışan maliyeti ve vergi politikası kriterleri; fayda tipi kriterler satış tahmini (talep), depo kapasitesi, teslim süresi, çeşitli taşıma opsiyonlarının varlığı, müşterilere yakınlık, tedarikçilere yakınlık, üreticilere yakınlık, arazi uygunluğu, altyapı (su, telekomünikasyon, elektrik) ve güvenlik kriterleridir.

\section{Yöntem}

Çalışmanın bu bölümünde bulanık Analitik Hiyerarşi Süreci (AHS) ve bulanık TODIM yöntemi açıklanmıştır. Bulanık mantık kullanılmasının sebebi, bulanık mantık teorisinin karar verme sürecindeki belirsizlikler ile uğraşırken insan yargılarının öznelliğini ve belirsizliğini aşma becerisidir. Bulanık AHS kullanmanın sebebi, bir hiyerarşi içinde ilgili kriterlerin ağırlıklarını hesaplama becerisinden yararlanmaktır. TODIM alternatifleri sıralayabilme kabiliyeti nedeniyle tercih edilmiştir. Bu nedenle, bu çalışmada, bulanık AHS ve Bulanık TODIM tekniği, her ikisinin de avantajlarını bir karar verme sürecinde kullanmak üzere entegre edilmiştir. 


\subsection{Bulanık $A H S$}

Saaty (1980) tarafindan bulunan AHS en çok kullanılan çok kriterli karar verme tekniklerinden birisidir. AHS kalitatif ve kantitatif kriterleri yönetme kapasitesi ile bilinir (Chung vd., 2005).

AHS'nin belirsiz karar verme süreçlerinde sınırlı uygulanabilirliği vardır (Önüt vd., 2009). Zadeh (1965), insan yargısının öznelliğini ve belirsizliğini aşmak için dilsel terimlerin kullanımını ortaya çıkarmak amacıyla bulanık küme teorisini geliştirmiştir. Bulanık bir küme temsil edildiğinde bir tilde işareti ( ) yerleştirilir (Zadeh, 1965).

Çeşitli bulanık üyelik kümeleri vardır. Bu çalışmada, sırasıyla mümkün olan en küçük, en olası ve mümkün olan en büyük değerleri ifade eden $\left(\mathrm{l}_{\mathrm{ij}}, \mathrm{m}_{\mathrm{ij}}, \mathrm{r}_{\mathrm{ij}}\right.$ ) olarak gösterilen üçgen bulanık sayılar kullanılmıştır (Kahraman vd., 2003, Önüt vd., 2009).

AHS metodolojisinin bulanık versiyonu Saaty'nin (1980) yaklaşımından farklıdır, çünkü bulanık küme teorisini içerir (Duran ve Aguilo, 2008; Kılınççı ve Önal, 2011). Bulanık sayılar, bulanık AHS'de ikili karşılaştırma matrislerini oluşturmak için kullanılır. Bulanık değerlendirme vektörü, her bir kriter için ikili karşılaştırmalar kullanılarak elde edilir. Saaty'nin (1980) 1-9 ölçeğinin basitlik ve kullanım kolaylığı gibi avantajları olmasına rağmen, insan yargısının öznelliğini ve belirsizliğini aşmak için dilsel terimlerinin kullanılması önerilir. Herhangi bir AHS analizinin sonuçlarının tutarlı olup olmadığını kontrol etmek için tutarlılık oranı hesaplanmalıdır.

\subsection{TODIM}

TODIM, Portekizce bir kısaltmadır ve İnteraktif ve Çok kriterli Karar Verme anlamına gelmektedir (Gomes vd., 2009; Ren vd., 2016). TODIM, Beklenti Teorisi uygulamasıyla global değer ölçümlerini kullanır (Gomes vd., 2009). TODIM yöntemi aynı zamanda bir ölçüt hiyerarşisi, bulanık değer yargıları ve değer yargıları için karşılıklı bağımlılık ilişkileri kullanılarak sözlü bir ölçeğin kullanılmasına izin verir (Tseng vd., 2014).

TODIM yönteminin temel amacı, potansiyel teori temelli fayda fonksiyonunu kullanarak her alternatifin diğerlerine göre baskınlık derecesini belirlemektir (Qin vd., 2017). Bir alternatifin diğerine göreli baskınlığını hesaplamak için ikili karşılaştırmalar yapılır (Gomes ve Rangel, 2009).

Matristeki değerlerin normalleştirilmesi, bir alternatifin değerinin her kuruluş için tüm alternatiflerin toplamına bölünmesiyle yapılır. $A_{1}, A_{2}, \ldots, A_{m}$ 'nin alternatifler olarak, $C_{1}, C_{2}, \ldots, C_{n}$ 'nin kriterler olarak belirlendiği bir matriste $\mathrm{P}_{\mathrm{ij}}$, alternatif $\mathrm{A}_{\mathrm{i}}$ 'nin $\mathrm{C}_{\mathrm{j}}$ kriterine göre derecelendirilmesidir. $\mathrm{T}, \omega_{\mathrm{j}} \in[0,1]$ ve $\sum_{j=1}^{n} \omega \mathrm{j}=1$ koşullarını yerine getiren $\mathrm{C}=\mathrm{C}=$ $\left\{\mathrm{C}_{1}, \mathrm{C}_{2}, \ldots, \mathrm{C}_{\mathrm{n}}\right\}$ kriter setiyle ilişkili ağırlık vektörüdür.

Matematiksel formülasyonlar sistematik olarak aşağıdaki gibi özetlenebilir (Gomes vd., 2009; Qin vd., 2017):

Adım 1: $C_{j}$ kriterinin referans ölçüt $C_{r}{ }^{\prime} e$ nispi ağırlığının $\left(\omega_{i r}\right)$ hesaplanması aşağıda gösterilmiştir.

$\omega_{\mathrm{jr}}=\omega_{\mathrm{j}} / \omega_{\mathrm{r}}(\mathrm{j}=1,2, \ldots, \mathrm{n})$

$\omega_{\mathrm{j}}, \mathrm{C}_{\mathrm{j}}$ ölçütünün ağırlığını gösterir.

Adım 2: $C_{j}$ kriteri açısından her bir alternatif $A_{i}$ 'nin her bir alternatif $A_{k}$ üzerindeki baskınlık derecesinin hesaplanması aşağıda gösterilmiştir.

$$
\Phi_{c}\left(A_{i}, A_{k}\right)=\left\{\begin{array}{l}
\sqrt{\frac{w_{j k}\left(P_{i j}-P_{k j}\right)}{\sum_{j=1}^{m} w_{j k}}} \text { if } P i j-P k j>0 \\
0 \quad \text { if } P i j-P k j=0 \\
\frac{-1}{\theta} \sqrt{\frac{\left(\sum_{j=1}^{n} w_{j k}\right)\left(P_{k j}-P_{i j}\right)}{w_{j k}}} \text { if } P \text { ij }-P k j<0
\end{array}\right.
$$

Bu denklemde, $\theta$ atenüasyon katsayısını temsil eder. $\theta$ değiştirildiğinde, teorik değer fonksiyonunun şekilleri negatif çeyrekte değişir. Bu parametrenin değer aralığı $\theta>0 ; 0<\theta<1$ ise, kaybın etkisi artar; $\theta>1$ ise, kaybın etkisi azalır.

Adım 3: $C_{j}$ kriteri açısından her alternatif $A_{i}$ 'nin $A_{k}$ üzerindeki genel baskınlık derecesinin hesaplanması aşağıda gösterilmiştir. 


$$
\delta\left(A_{i}, A_{k}\right)=\sum_{j=1}^{n} \Phi_{j}\left(A_{i}, A_{k}\right)
$$

potansiyel değeri hesaplanır.

Adım 4: Aşağıdaki denklem kullanılarak alternatif $\mathrm{A}_{\mathrm{i}}^{\prime} \operatorname{nin}(\mathrm{i}=1,2, \ldots, \mathrm{m})$ global

$$
\xi_{i}=\frac{\sum_{k=1}^{m} \delta\left(A_{i}, A_{k}\right)-\min \sum_{k=1}^{m} \delta\left(A_{i}, A_{k}\right)}{\max \sum_{k=1}^{m} \delta\left(A_{i}, A_{k}\right)-\min \sum_{k=1}^{m} \delta\left(A_{i}, A_{k}\right)} .
$$

Adım 5: Alternatiflerin global potansiyel değerlerine dayanarak sıralama tamamlanmalıdır. Değerdeki artış en iyi alternatif $\mathrm{A}_{i}{ }^{\prime} \mathrm{yi}$ temsil eder.

\section{Uygulama ve Sonuçlar}

Bu çalışmanın uygulaması, Türkiye'nin en büyük perakende satış zinciri firmalarından birinin İzmir'de bulunan yönetim ofisinde gerçekleştirilmiştir. Bu çalışmanın uygulamasının perakende sektöründe gerçekleştirilmesinin sebebi, perakende sektöründeki depolama faaliyetinin, sektörün en önemli faaliyetlerinden biri olmasıdır.

İki farklı veri toplanmıştır. Birincisi, faktörlerin önem ağırlıklarını bulmak amacıyla kullanılan Bulanık AHS yöntemi için ikili karşılaştırma matrisi verilerini, ikincisi ise, kuruluşun bütün faktörler göz önüne alınarak en uygun depo yerinin seçiminde kullanılacak olan Bulanık TODIM için ikili karşılaştırma matris verilerini içermektedir. Veri toplama süreci, kuruluşun tedarik zinciri ve depo faaliyetlerinden sorumlu yetkililerinin değerlendirmeleri ile yürütülmüştür. Genel müdür, tedarik zinciri müdürü, tedarik zinciri müdür yardımcısı, satın alma müdürü ve tedarik zinciri departmanında çalışan 6 kişiden oluşan toplam 10 kişinin katıldığ 1 veri toplama süreci, yönetim kurulunun denetimi dâhilinde gerçekleşmiştir.

10 farklı uzmandan elde edilen ikili karşılaştırma matrisleri vasıtasıyla faktörlerin önem ağırlıkları Bulanık AHS yöntemi kullanılarak elde edilmiştir. Tablo 3, faktörlerin önem ağırlıklarını göstermektedir.

Tablo 3. Kriterlerin Önem Ağırlıkları

\begin{tabular}{|c|c|}
\hline Kriterler & Normalize Edilmiş Önem Ă̆ırlıkları \\
\hline Taşıma Maliyeti & 0,16 \\
\hline Satış Tahmini (Talep) & 0,07 \\
\hline Depo Yatırım Maliyeti & 0,13 \\
\hline Depo Kapasitesi & 0,05 \\
\hline Teslim Süresi & 0,06 \\
\hline Çalışan Maliyeti & 0,07 \\
\hline Çeşitli Taşıma Opsiyonlarının Varlığı & 0,07 \\
\hline Müşterilere Yakınlık & 0,08 \\
\hline Tedarikçilere Yakınlık & 0,05 \\
\hline Üreticilere Yakınlık & 0,06 \\
\hline Arazi Uygunluğu & 0,04 \\
\hline Vergi Politikası & 0,04 \\
\hline Altyapı (Su, Telekomünikasyon, Elektrik) & 0,07 \\
\hline Güvenlik & 0,04 \\
\hline
\end{tabular}


Yapılan analize göre, en uygun depo yeri seçimi için en önemli faktör, 0,16 önem ağırlığı ile taşıma maliyeti olarak bulunmuştur. Depo Yatırım Maliyeti 0,13 ile ikinci en önemli, Müşterilere Yakınlık 0,08 ile en önemli üçüncü faktör olarak hesaplanmıştır.

Depo yeri seçimi için alternatifler, Torbalı, Menemen, Kemalpaşa, Çiğli ve Bayraklı olarak belirlenmiştir. Bu alternatifler firmanın tercihidir. Alternatifler için ikili karşılaştırma matrisleri düzenlenmiş ve TODIM yöntemi ile en iyi alternatif bulunmuştur.

Tablo 4'te görülebilen sonuçlar, en iyi alternatifin Torbalı olduğunu göstermektedir. Bayraklı ve Menemen depoları sırasıyla ikinci ve üçüncü en iyi alternatif olarak kabul edilebilir. Atenüasyon katsayısı literatürde genel kabul gördüğü haliyle 2,25 olarak kullanılmıştır.

Tablo 4. Global Değerler, Alternatif Sıralaması

\begin{tabular}{|c|c|}
\hline Depo Alternatifleri & Global Değerler \\
\hline Torbalı & 1 \\
\hline Bayraklı & 0,724473876 \\
\hline Menemen & 0,462520379 \\
\hline Kemalpaşa & 0,13876849 \\
\hline Çiğli & 0 \\
\hline
\end{tabular}

Alternatifler arasındaki hassasiyeti belirtmek için farklı atenüasyon katsayı değerleri kullanılarak yapılan hassasiyet analizi sonuçları Tablo 5'te görülmektedir. Atenüasyon katsayısı sırasıyla 2, 1 ve 2,5 olarak kullanılmıştır. Farklı atenüasyon katsayılarına göre sonucun değişmediği görülmüştür.

Tablo 5. Hassasiyet Analizi (Global Değerler, Alternatif Sıralaması)

\begin{tabular}{|c|c|c|c|}
\hline Depo Alternatifleri & Global Değerler $(\boldsymbol{\theta}=\mathbf{2})$ & Global Değerler $(\boldsymbol{\theta}=\mathbf{1})$ & Global Değerler $(\boldsymbol{\theta}=\mathbf{2 , 5})$ \\
\hline Torbalı & 1 & 1 & 1 \\
\hline Bayraklı & 0,743716384 & 0,83077096 & 0,70610281 \\
\hline Menemen & 0,48031107 & 0,560797511 & 0,445535382 \\
\hline Kemalpaşa & 0,129295237 & 0,086437517 & 0,147812724 \\
\hline Çiğli & 0 & 0 & 0 \\
\hline
\end{tabular}

\section{Tartışma}

Günümüzün hızla gelişen iş dünyasında, tedarik zinciri yönetimi gittikçe daha önemli hale gelmektedir. Tedarik zinciri yönetimi, mal akışı, ne üretilmesi, ne kadar üretilmesi ve farklı seviyelerde bilgi paylaşımı ile ilgili olmanın yanı sıra, sürecin her aşamasında ne kadar depolanacağı ve en önemlisi yerel veya küresel depo yeri seçilmesi ile ilgilidir. Depo yeri seçimi bu nedenle tedarik zinciri üzerindeki etkisi nedeniyle önemli bir karar sorunudur.

Bu çalışmada, perakende sektöründe faaliyet gösteren bir firmanın en uygun depo yeri seçiminin, bulanık Analitik Hiyerarşi Süreci (AHS) ve bulanık TODIM teknikleri entegre edilerek bulunması hedeflenmiştir. En uygun depo yeri seçimi için geliştirilen kriter seti, diğer bir deyişle kavramsal çerçeve, literatür taraması ile geliştirilmiştir. Bulanık AHS kriterlerin önem ağırlıklarının bulunmasında kullanılmış, alternatifler ise bulanık TODIM tekniği kullanılarak değerlendirilmiştir. Bu çalışmanın özgün niteliği, 1) depo yeri seçimi için geliştirilen kriter setinin kapsayıcı olması, 2) TODIM tekniğinin depo yeri seçimi için kullanılmasıdır.

Yapılan analize göre, en uygun depo yeri seçimi için en önemli faktör, 0,16 önem ağırlığı ile taşıma maliyeti olarak bulunmuştur. Depo Yatırım Maliyeti 0,13 ile ikinci en önemli, Müşterilere Yakınlık 0,08 ile en önemli üçüncü faktör olarak hesaplanmıştır. Torbalı, Menemen, Kemalpaşa, Çiğli ve Bayraklı olarak belirlenen alternatiflerin içindeki en iyisi Torbalı olarak bulunmuştur.

Bu araştırmanın temel kısıtlılığı araştırmanın öznel yargılara dayanıyor olmasıdır. Ayrıca, vaka çalışması gelişmekte olan bir ülkede, Türkiye'de gerçekleştirilmiştir. Gelecekteki çalışmalar önerilen kavramsal çerçeveyi Türkiye'deki farklı sektörlerde ve diğer gelişmekte olan ülkelerde uygulamaya odaklanabilir. Kriterlerin önem ağırlıkları, alternatiflerin sıralanması başka çok kriterli karar verme teknikleri ile hesaplanabilir. 


\section{KAYNAKÇA}

Abo-Elnaga, Y., El-Sobky, B. ve Al-Naser, L. (2017). “An active-set trust-region algorithm for solving warehouse location problem". Journal of Taibah University for Science, 11, 353-358.

Aghezzaf, E. (2005). "Capacity planning and warehouse location in supply chains with uncertain demands". Journal of the Operational Research Society, 56(4), 453-462.

Aktepe, A. ve Ersöz, S. (2014). “AHP-VIKOR ve MOORA Yöntemlerinin Depo Yeri Seçim Probleminde Uygulanması”. Endüstri Mühendisliği Dergisi, 25(1-2), 2-15.

Amiri, A. (2006). "Designing a distribution network in a supply chain system: formulation and efficient solution procedure". European Journal of Operational Research, 171, 567-576.

Askin, R.G., Baffo, I. ve Xia, M. (2014). "Multi-commodity warehouse location and distribution planning with inventory consideration". International Journal of Production Research, 52(7), 1897-1910.

Baker, B.M. (1982). "Linear Relaxations of the Capacitated Warehouse Location Problem". The Journal of the Operational Research Society, 33(5), 475-479.

Benalcazar, P., Kaminski, J. ve Saluga, P.W. (2017). "The storage location problem in a coal supply chain: background and methodological approach". Mineral Resources Management, 33(1), 5-14.

Bhatnagar, R. ve Sohal, A.S. (2005). "Supply chain competitiveness: measuring the impact of location factors, uncertainty and manufacturing practices". Technovation, 25, 443-456.

Brahimi, N. ve Khan, S.A. (2014). "Warehouse location with production, inventory, and distribution decisions: a case study in the lube oil industry". 4OR-A Quarterly Journal of Operations Research, 12, 175-197.

Brunaud, B., Bassett, M.H., Agarwal, A., Wassick, J.M. ve Grossmann, I.E. (2018). "Efficient formulations for dynamic warehouse location under discrete transportation costs". Computers and Chemical Engineering, 111, 311-323.

Chatterjee, K. ve Kar, S. (2013). “An Induced Fuzzy Rasch-VIKOR Model for Warehouse Location Evaluation under Risky Supply Chain”. In: International Conference on Pattern Recognition and Machine Intelligence, PREMI 2013. Lecture Notes in Computer Science, vol. 8251. Springer, Berlin, Heidelberg.

Chen, C., Liu, J., Li, Q., Wang, Y., Xiong, H. ve Wu, S. (2017). "Warehouse Site Selection for Online Retailers in Interconnected Warehouse Networks". IEEE International Conference on Data Mining.

Chung, S.H., Lee, A.H. ve Pearn, W.L. (2005). "Product mix optimization for semiconductor manufacturing based on AHP and ANP analysis". International Journal of Advanced Manufacturing Technology, 25, 1144-1156.

da Silva, D.D., de Vasconcelos, N.V.C. ve Cavalcante, C.A.V. (2015). "Multicriteria Decision Model to Support the Assignment of Storage Location of Products in a Warehouse". Mathematical Problems in Engineering, 2015, Makale No. 481950, 8 sayfa.

Demirel, T., Demirel, N.C. ve Kahraman, C. (2010). "Multi-criteria warehouse location selection using Choquet integral". Expert Systems with Applications, 37, 3943-3952.

Dey, B., Bairagi, B., Sarkar, B. ve Sanyal, S.K. (2016). "Warehouse location selection by fuzzy multicriteria decision making methodologies based on subjective and objective criteria". International Journal of Management Science and Engineering Management, 11(4), 262-278.

Dey, B., Bairagi, B., Sarkar, B. ve Sanyal, S.K. (2017). “Group heterogeneity in multi member decision making model with an application to warehouse location selection in a supply chain”. Computers \& Industrial Engineering, 105, 101-122.

Duran, O ve Aguilo, J. (2008). “Computer-aided machine-tool selection based on a Fuzzy-AHP approach". Expert Systems with Applications, 34, 1787-1794.

Durmuş, A., ve Türk, S.S. (2014). "Factors Influencing Location Selection of Warehouses at the Intra-Urban Level: Istanbul Case". European Planning Studies, 22(2), 268-292.

Emeç, Ş. ve Akkaya, G. (2018). "Stochastic AHP and fuzzy VIKOR approach for warehouse location selection problem". Journal of Enterprise Information Management, 31(6), 950-962.

Gill, A. ve Bhatti, M.I. (2007). “Optimal model for warehouse location and retailer allocation”. Applied Stochastic Models in Business and Industry, 23, 213-221.

Gomes, L.F.A.M. ve Rangel, L.A.D. (2009). “An application of the TODIM method to the multicriteria rental evaluation of residential properties". European Journal of Operational Research, 193, 204-211.

Gomes, L.F.A.M., Rangel, L.A.D. ve Maranhao, F.J.C. (2009). "Multicriteria analysis of natural gas destination in Brazil: An application of the TODIM method". Mathematical and Computer Modelling, 50, 92-100.

Hakim, R.T. ve Kusumastuti, R.D. (2018). "Model to Determine Relief Warehouse Location in East Jakarta Using the Analytic Hierarchy Process". International Journal of Technology, 7, 1405-1414.

He, J., Feng, C., Hu, D. ve Liang, L. (2017). “A Decision Model for Emergency Warehouse Location Based on a Novel Stochastic MCDA Method: Evidence from China”. Mathematical Problems in Engineering, 2017, Makale No. 7804781, 10 sayfa.

Heizer, J. ve Render, B. (2006). “Operations Management”. 8th ed. Pearson Prentice Hall, Upper Saddle River, NJ.

Kahraman, C., Ruan, D. ve Dogan, I. (2003). "Fuzzy group decision making for facility location selection”. Information Sciences, 157, 135-153. 
Kalfakakou, R., Katsavounis, S. ve Tsouros, K. (2003). "Minimum number of warehouses for storing simultaneously compatible products". International Journal of Production Economics, 81-82, 559-564.

Kapoor, V., Tak, S.S. ve Sharma, V. (2008). "Location selection: a fuzzy clustering approach". International Journal of Fuzzy Systems, 10(2), 123-128.

Kılınçç1, O., ve Önal, S.A. (2011). "Fuzzy AHP approach for supplier selection in a washing machine company”. Expert Systems with Applications, 38, 9656-9664.

Michel, L. ve Van Hentenryck, P. (2004). “A simple tabu search for warehouse location”. European Journal of Operational Research, 157, 576-591.

Onstein, A.T.C., Tavasszy, L.A. ve van Damme, D.A. (2019). "Factors determining distribution structure decisions in logistics: a literature review and research agenda". Transport Reviews, 39:2, 243-260.

Önüt, S., Kara, S.S. ve Isik, E. (2009). "Long term supplier selection using a combined fuzzy MCDM approach: A case study for a telecommunication company". Expert Systems with Applications, 36, 3887-3895.

Özcan, T., Çelebi, N. ve Esnaf, Ş. (2011). "Comparative analysis of multi-criteria decision making methodologies and implementation of a warehouse location selection problem". Expert Systems with Applications, 38, 9773-9779.

Qin, J., Liu, X. ve Pedrycz, W. (2017). “An extended TODIM multi-criteria group decision making method for green supplier selection in interval type-2 fuzzy environment". European Journal of Operational Research, 258(2), 626638.

Queiruga, D., Walther, G., Gonzalez-Benito, J. ve Spengler, T. (2008). "Evaluation of sites for the location of WEEE recycling plants in Spain". Waste Management, 28, 181-190.

Rath, S. ve Gutjahr, W.J. (2014). "A math-heuristic for the warehouse location-routing problem in disaster relief". Computers \& Operations Research, 42, 25-39.

Ren, P., Xu, Z. ve Gou, X. (2016). "Pythagorean fuzzy TODIM approach to multi-criteria decision making”. Applied Soft Computing, 42, 246-259.

Rouwenhorst, B., Reuter, B., Stockrahm, V., van Houtum, G.J., Mantel, R.J. ve Zijm, W.H.M. (2000). "Warehouse design and control: framework and literature review". European Journal of Operational Research, 122(3), 515-533.

Saaty, T.L. (1980). "The Analytic Hierarchy Process". McGraw-Hill, New York.

Singh, R.K., Chaudhary, N. ve Saxena, N. (2018). "Selection of warehouse location for a global supply chain: A case study". IIMB Management Review, 30, 343-356.

Snyder, L.V. (2006). "Facility location under uncertainty: a review", IIE Transactions, 38(7), 547-564.

Temur, G.T. (2016). "A novel multi attribute decision making approach for location decision under high uncertainty". Applied Soft Computing, 40, 674-682.

Tseng, M.L., Lin, Y.H., Tan, K., Chen, R.H. ve Chen, Y.H. (2014).” Using TODIM to evaluate green supply chain practices under uncertainty". Applied Mathematical Modelling, 38(11), 2983-2995.

Yaobao, Z., Ping, H. ve Shu, Y. (2013). "An Improved Particle Swarm Optimization for the Automobile Spare Part Warehouse Location Problem”. Mathematical Problems in Engineering, 2013, Makale no. 726194, 6 sayfa.

Zadeh, L.A. (1965). "Fuzzy sets”. Information Control, 8, 338-353. 